NBER WORKING PAPER SERIES

\title{
CHAOTIC INTEREST RATE RULES: EXPANDED VERSION
}

\author{
Jess Benhabib \\ Stephanie Schmitt-Grohe \\ Martin Uribe \\ Working Paper 10272 \\ http://www.nber.org/papers/w10272 \\ NATIONAL BUREAU OF ECONOMIC RESEARCH \\ 1050 Massachusetts Avenue \\ Cambridge, MA 02138 \\ January 2004
}

We thank for comments seminar participants at the 2001 NBER Summer Institute and for technical assistance the C.V. Starr Center of Applied Economics at New York University. The views expressed herein are those of the authors and not necessarily those of the National Bureau of Economic Research.

(C2004 by Jess Benhabib, Stephanie Schmitt-Grohe, and Martin Uribe. All rights reserved. Short sections of text, not to exceed two paragraphs, may be quoted without explicit permission provided that full credit, including (C) notice, is given to the source. 
Chaotic Interest Rate Rules: Expanded Version

Jess Benhabib, Stephanie Schmitt-Grohe, and Martin Uribe

NBER Working Paper No. 10272

January 2004

JEL No. E52, E31, E63

\section{$\underline{\text { ABSTRACT }}$}

A growing empirical and theoretical literature argues in favor of specifying monetary policy in the form of Taylor-type interest rate feedback rules. That is, rules whereby the nominal interest rate is set as an increasing function of inflation with a slope greater than one around an intended inflation target. This paper shows that such rules can easily lead to chaotic dynamics. The result is obtained for feedback rules that depend on contemporaneous or expected future inflation. The existence of chaotic dynamics is established analytically and numerically in the context of calibrated economies. The battery of fiscal policies that has recently been advocated for avoiding global indeterminacy induced by Taylor-type interest-rate rules (such as liquidity traps) are shown to be unlikely to provide a remedy for the complex dynamics characterized in this paper.

Jess Benhabib

Department of Economics

New York University

269 Mercer Street

New York, NY 10003

jess.benhabib@nyu.edu

\author{
Stephanie Schmitt-Grohe \\ Department of Economics \\ Duke University \\ P.O. Box 90097 \\ Durham, NC 27708 \\ and NBER \\ grohe@duke.edu
}

\author{
Martin Uribe \\ Department of Economics \\ Duke University \\ P.O. Box 90097 \\ Durham, NC 27708 \\ and NBER \\ uribe@duke.edu
}




\section{Introduction}

In much of the recent literature on monetary economics it is assumed that monetary policy takes the form of an interest-rate feedback rule whereby the central bank sets the nominal interest rate as a function of some measure of inflation and the level of aggregate activity. One justification for this modeling strategy is empirical. Several authors, beginning with Taylor (1993) have documented that the central banks of major industrialized countries implement monetary policy through interest-rate feedback rules of this type. ${ }^{1}$ These empirical studies have further shown that since the early 1980s interest-rate feedback rules in developed countries have been active in the sense that the nominal interest rate responds more than one for one to changes in the inflation measure. For example, Taylor (1993) finds that for the U.S. during the post-Volker era, the inflation coefficient of the interest-rate feedback rule is about 1.5 .

In his seminal paper, Taylor (1993) also argues on theoretical grounds that active interestrate feedback rules - which have become known as Taylor rules - are desirable for aggregate stability. The essence of his argument is that if in response to an increase in inflation the central bank raises nominal interest rates by more than the increase in inflation, the resulting increase in real interest rates will tend to slowdown aggregate demand thereby curbing inflationary pressures. Following Taylor's influential work, a large body of theoretical research has argued in favor of active interest rate rules. One argument in favor of Taylortype rules is that they guarantee local uniqueness of the rational expectations equilibrium. ${ }^{2}$

The validity of the view that Taylor rules induce determinacy of the rational expectations equilibrium has been challenged in two ways. First, it has been shown that local determinacy of equilibrium under active interest-rate rules depends crucially on the assumed preference and technology specification and as well as on the nature of the accompanying fiscal regime (Leeper, 1991; Benhabib, Schmitt-Grohé and Uribe, 2001b, Carlstrom and Fuerst, 2000 and 2001a, and Dupor, 1999). Second, even in cases in which active interest-rate rules guarantee uniqueness of the rational expectations equilibrium locally, they may fail to do so globally. Specifically, Benhabib, Schmitt-Grohé, and Uribe (2001a) and Schmitt-Grohé and Uribe $(2000 \mathrm{a}, \mathrm{b})$ show that interest-rate rules that are active around some inflation target give rise to liquidity traps. That is, to unintended equilibrium dynamics in which inflation falls to a low and possibly negative long-run level and the nominal rate falls to a low and possibly zero level.

In this paper, we identify a third form of instability that may arise under Taylor-type policy rules. Specifically, we show that active interest-rate rules may open the door to equilibrium cycles of any periodicity and even chaos. These equilibria feature trajectories that converge neither to the intended steady state nor to an unintended liquidity trap. Rather the economy cycles forever around the intended steady state in a periodic or aperiodic fashion. Interestingly, such equilibrium dynamics exist precisely when the target equilibrium is unique from a local point of view. That is, when the inflation target is the only equilibrium level of inflation within a sufficiently small neighborhood around the target itself.

We establish the existence of periodic and chaotic equilibria analytically in the context

\footnotetext{
${ }^{1}$ See for instance Clarida, Galí, and Gertler (1998), Clarida and Gertler (1997), and Taylor (1999).

${ }^{2}$ See, for example, Leeper (1991), Rotemberg and Woodford (1999), and Clarida, Galí, and Gertler (2000).
} 
of a simple, discrete-time, flexible-price, money-in-the-production-function economy. For analytical convenience, we restrict attention to a simplified Taylor rule in which the nominal interest rate depends only on inflation. We consider two types of interest rate feedback rules. In one the argument of the feedback rule is a contemporaneous measure of inflation and in the other the central bank responds to expected future inflation. We show that the theoretical possibility of complex dynamics exists under both specifications of the interest rate feedback rule. To address the empirical plausibility of periodic and chaotic equilibria, we show that these complex dynamics arise in a model that is calibrated to the U.S. economy.

The remainder of the paper is organized in four sections. Section 2 presents the basic theoretical framework and characterizes steady-state equilibria. Section 3 demonstrates the existence of periodic and chaotic equilibria under a forward-looking interest-rate rule. Section 4 extends the results to the case of Taylor-type rules whereby the nominal interest rate depends upon a contemporaneous measure of inflation. Finally, section 5 discusses the robustness of the results to a number of variations in the economic environment. It shows that periodic equilibria also exist when the Taylor rule is globally linear and does not respect the zero bound on nominal rates. In addition it considers the consequences of assuming that money affects output with lags. The section closes with a brief discussion about learnability of the equilibria studied in the paper and the design of policies geared at restoring uniqueness.

\section{The economic environment}

\subsection{Households}

Consider an economy populated by a large number of infinitely lived agents with preferences described by the following utility function:

$$
\sum_{t=0}^{\infty} \beta^{t} \frac{c_{t}^{1-\sigma}}{1-\sigma} ; \quad \sigma>0, \beta \in(0,1)
$$

where $c_{t}$ denotes consumption in period $t$. Agents have access to two types of financial asset: fiat money, $M_{t}$, and government bonds, $B_{t}$. Government bonds held between periods $t$ and $t+1$ pay the gross nominal interest rate $R_{t}$. In addition, agents receive a stream of real income $y_{t}$ and pay real lump-sum taxes $\tau_{t}$. The budget constraint of the representative household is then given by

$$
M_{t}+B_{t}+P_{t} c_{t}+P_{t} \tau_{t}=M_{t-1}+R_{t-1} B_{t-1}+P_{t} y_{t},
$$

where $P_{t}$ denotes the price level in period $t$. Letting $a_{t} \equiv\left(M_{t}+B_{t}\right) / P_{t}$ denote real financial wealth in period $t, m_{t} \equiv M_{t} / P_{t}$ denote real money balances, and $\pi_{t} \equiv P_{t} / P_{t-1}$ the gross rate of inflation, the above budget constraint can be written as

$$
a_{t}+c_{t}+\tau_{t}=\frac{\left(1-R_{t-1}\right)}{\pi_{t}} m_{t-1}+\frac{R_{t-1}}{\pi_{t}} a_{t-1}+y_{t}
$$

To prevent Ponzi games, households are subject to a borrowing constraint of the form

$$
\lim _{t \rightarrow \infty} \frac{a_{t}}{\prod_{j=0}^{t-1}\left(R_{j} / \pi_{j+1}\right)} \geq 0 .
$$


We motivate a demand for money by assuming that real balances facilitate firms transactions as in Calvo (1979), Fischer (1974), and Taylor (1977). Specifically, we assume that output is an increasing and concave function of real balances. Formally,

$$
y_{t}=f\left(m_{t}\right)
$$

Households choose sequences $\left\{c_{t}, m_{t}, y_{t}, a_{t}\right\}_{t=0}^{\infty}$ so as to maximize the utility function (1) subject to (2)-(4), given $a_{-1}$. The first-order optimality conditions are constraints (2)-(4) holding with equality and

$$
\begin{gathered}
c_{t}^{-\sigma}=\beta c_{t+1}^{-\sigma} \frac{R_{t}}{\pi_{t+1}} \\
f^{\prime}\left(m_{t}\right)=\frac{R_{t}-1}{R_{t}} .
\end{gathered}
$$

The first optimality condition is a standard Euler equation requiring that in the margin a dollar spent on consumption today provides as much utility as that dollar saved and spent tomorrow. The second condition says that the marginal productivity of money at the optimum is equal to the opportunity cost of holding money, $\left(R_{t}-1\right) / R_{t}$.

\subsection{The monetary/fiscal policy regime}

Following a growing recent empirical literature that has attempted to identify systematic components in monetary policy, we postulate that the government conducts monetary policy in terms of an interest rate feedback rule of the form

$$
R_{t}=\rho\left(\pi_{t+j}\right) ; \quad j=0 \text { or } 1 .
$$

We consider two cases: forward-looking interest rate feedback rules $(j=1)$ and contemporaneous interest rate feedback rules $(j=0)$. Under contemporaneous feedback rules the central bank sets the current nominal interest rate as a function of the inflation rate between periods $t-1$ and $t$. We also analyze the case of forward-looking rules because a number of authors have argued that in the post-Volker era, U.S. monetary policy is better described as incorporating a forward-looking component (see Clarida et al., 1998; Orphanides, 1997).

We impose four conditions on the functional form of the interest-rate feedback rule: First, in the spirit of Taylor (1993) we assume that monetary policy is active around a target rate of inflation $\pi^{*}>\beta$; that is, the interest elasticity of the feedback rule at $\pi^{*}$ is greater than unity, or $\rho^{\prime}\left(\pi^{*}\right) \pi^{*} / \rho\left(\pi^{*}\right)>1$. Second, we impose the restriction $\rho\left(\pi^{*}\right)=\pi^{*} / \beta$, which ensures the existence of a steady-state consistent with the target rate of inflation. Third, we assume that the feedback rule satisfy (strictly) the zero bound on nominal interest rates, $\rho(\pi)>1$ for all $\pi$. Finally, we assume that the feedback rule is nondecreasing, $\rho^{\prime}(\pi) \geq 0$ for all $\pi$.

Government consumption is assumed to be zero. Thus, each period the government faces the budget constraint $M_{t}+B_{t}=M_{t-1}+R_{t-1} B_{t-1}-P_{t} \tau_{t}$. This constraint can be written in real terms in the following form:

$$
a_{t}=\frac{R_{t-1}}{\pi_{t}} a_{t-1}-\left[\frac{R_{t-1}-1}{\pi_{t}} m_{t-1}+\tau_{t}\right] .
$$


This expression states that total government liabilities in period $t, a_{t}$, are given by liabilities carried over from the previous period, including interest, $R_{t-1} / \pi_{t} a_{t-1}$, minus total consolidated government revenues, given by the expression in square brackets on the right-hand side. Consolidated government revenues, in turn, have two components: seignorage revenue, $\left[\left(R_{t-1}-1\right) / \pi_{t}\right] m_{t-1}$, and regular taxes, $\tau_{t}$.

We assume that the fiscal regime consists of setting consolidated government revenues as a fraction of total government liabilities. Formally,

$$
\frac{R_{t-1}-1}{\pi_{t}} m_{t-1}+\tau_{t}=\omega a_{t-1} ; \quad \omega>0 .
$$

Combining the above two expressions, (8) and (9), we obtain:

$$
a_{t}=\left(\frac{R_{t-1}}{\pi_{t}}-\omega\right) a_{t-1}
$$

Given our maintained assumption that $\omega>0$, this expression implies that

$$
\lim _{t \rightarrow \infty} \frac{a_{t}}{\prod_{j=0}^{t-1}\left(R_{j} / \pi_{j+1}\right)}=0 .
$$

Therefore, the assumed fiscal policy ensures that the household's borrowing limit holds with equality under all circumstances.

\subsection{Equilibrium}

Combining equations (2) and (8) implies that the goods market clears at all times:

$$
y_{t}=c_{t}
$$

We are now ready to define an equilibrium real allocation.

Definition 1 An equilibrium real allocation is a set of sequences $\left\{m_{t}, R_{t}, c_{t}, \pi_{t}, y_{t}\right\}_{t=0}^{\infty}$ satisfying $R_{t}>1$, (4)-(7) and (12).

Given $a_{-1}$ and any pair of equilibrium sequences $\left\{R_{t}, \pi_{t}\right\}_{t=0}^{\infty}$, equation (10) gives rise to a sequence $\left\{a_{t}\right\}_{t=0}^{\infty}$ that, as shown above, satisfies the transversality condition (11).

For analytical and computational purposes, we will focus on the following specific parameterizations of the monetary policy rule and the production function:

$$
R_{t}=\rho\left(\pi_{t+j}\right) \equiv 1+\left(R^{*}-1\right)\left(\frac{\pi_{t+j}}{\pi^{*}}\right)^{\frac{A}{\left(R^{*}-1\right)}} ; \quad R^{*}=\pi^{*} / \beta
$$

and

$$
f\left(m_{t}\right)=\left[a m_{t}^{\mu}+(1-a) \bar{y}^{\mu}\right]^{\frac{1}{\mu}} ; \quad \mu<1, a \in(0,1] .
$$

We assume that $A / R^{*}>1$, so that at the target rate of inflation the feedback rule satisfies the Taylor criterion $\rho^{\prime}\left(\pi^{*}\right) \pi^{*} / \rho\left(\pi^{*}\right)>1$. In other words, at the target rate of inflation, the interest-rate feedback rule is active. The parameter $\bar{y}$ is meant to reflect the presence of a 
Figure 1: Steady State equilibria

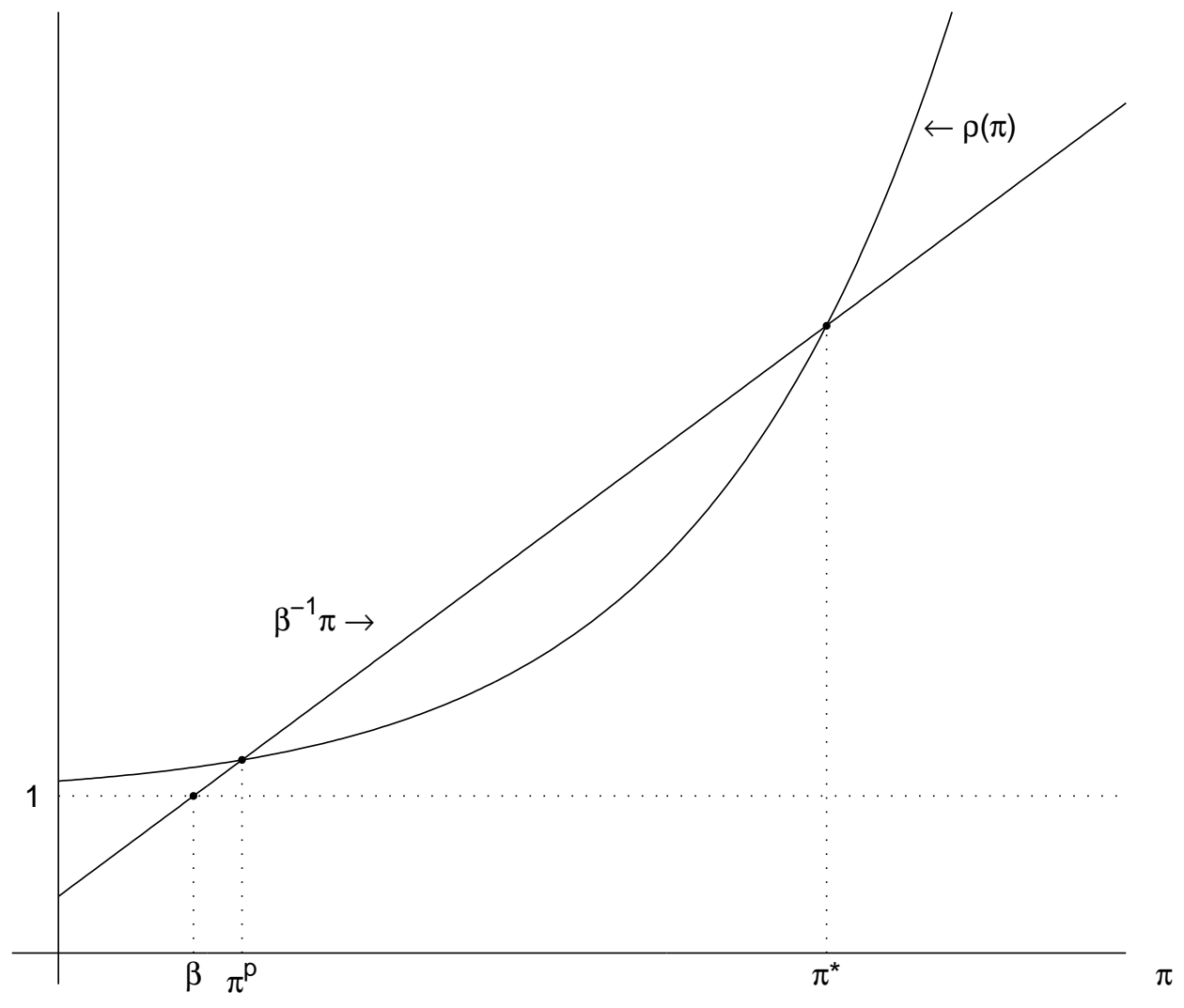

fixed factor of production. Under this production technology one may view real balances either as directly productive or as decreasing the transaction costs of exchange. ${ }^{3}$

With these particular functional forms, an equilibrium real allocation is defined as a set of sequences $\left\{m_{t}, R_{t}, c_{t}, \pi_{t}, y_{t}\right\}_{t=0}^{\infty}$ satisfying $R_{t}>1,(5),(6)$, and (12)-(14).

\subsection{Steady-state equilibria}

Consider constant solutions to the set of equilibrium conditions (5), (6), (12), (13), and (14). Because none of the endogenous variables entering in the equilibrium conditions is predetermined in period $t$ (i.e., all variables are 'jump' variables), such solutions represent equilibrium real allocations. We refer to this type of equilibrium as steady-state equilibria. By equation (5), the steady-state nominal interest rate $R$ is related to the steady-state inflation rate as $R=\beta^{-1} \pi$. In addition, the interest-rate feedback rule (13) implies that $R=\rho(\pi)$. Combining these two expressions, yields the steady-state condition

$$
\beta^{-1} \pi=\rho(\pi) .
$$

Figure 1 depicts the left- and right-hand sides of this condition for the particular functional form of $\rho(\pi)$ given in equation (13). Clearly, one steady-state value of inflation is the target

\footnotetext{
${ }^{3}$ It is also possible to replace the fixed factor $\bar{y}$ with a function increasing in labor, and add leisure to the utility function. The current formulation then would correspond to the case of an inelastic labor supply.
} 
inflation rate $\pi^{*}$. The slope of $\rho(\pi)$ at $\pi^{*}$ is $\beta^{-1} A / R^{*}$ which is greater than the slope of the left-hand side, $\beta^{-1}$. This means that at this steady state monetary policy is active. We therefore refer to this steady-state equilibrium as the active steady state, and denote the associated real allocation by $\left(y^{*}, c^{*}, m^{*}, R^{*}, \pi^{*}\right)$. The particular functional form assumed for the interest-rate feedback rule implies that $\rho(\pi)$ is strictly convex, strictly increasing, and strictly greater than one. Consequently, there exists another steady state value of inflation, $\pi^{p}$, which lies between $\beta$ and $\pi^{*}$. Thus, the steady-state interest rate associated with $\pi^{p}$, $R^{p}=\pi^{p} / \beta$ is strictly greater than one. Further, at this second steady state, the feedback rule is passive. To see this, note that $\rho^{\prime}\left(\pi^{p}\right)<\beta^{-1}$, which implies that $\rho^{\prime}\left(\pi^{p}\right) \pi^{p} / \rho\left(\pi^{p}\right)=$ $\rho^{\prime}\left(\pi^{p}\right) \beta<1$. Thus, we refer to this steady-state equilibrium as the passive steady state and denote the implied real allocation by $\left(y^{p}, c^{p}, m^{p}, R^{p}, \pi^{p}\right) .{ }^{4}$

\section{Equilibrium Dynamics Under Forward-Looking Interest- Rate Feedback Rules}

Consider the case in which the central bank sets the short-term nominal interest rate as a function of expected future inflation, that is, $j=1$ in equation (13).

Combining 6) and (14) yields the following negative relation between output and the nominal interest rate

$$
R_{t}=R\left(y_{t}\right) ; \quad R^{\prime}<0 .
$$

This expression together with (5), (12), and (13), implies a first-order, non-linear difference equation in output of the form:

$$
y_{t+1}=F\left(y_{t}\right) \equiv \beta^{1 / \sigma} y_{t}\left[\frac{R\left(y_{t}\right)}{\rho^{-1}\left(R\left(y_{t}\right)\right)}\right]^{1 / \sigma},
$$

where $\rho^{-1}(\cdot)$ denotes the inverse of the function $\rho(\cdot)$. Finding an equilibrium real allocation then reduces to finding a real positive sequence $\left\{y_{t}\right\}_{t=0}^{\infty}$ satisfying (16). ${ }^{5}$

\subsection{Local Equilibria}

Consider perfect-foresight equilibrium real allocations in which output remains forever in an arbitrarily small neighborhood around a steady state and converges to it. To this end, we log-linearize (16) around $y^{*}$ and $y^{p}$. This yields

$$
\widehat{y}_{t+1}=\left[1+\frac{\epsilon_{R}}{\sigma}\left(1-\frac{1}{\epsilon_{\rho}}\right)\right] \widehat{y}_{t},
$$

\footnotetext{
${ }^{4}$ For the steady-state levels of output and real balances to be well defined (i.e., positive real values), it is necessary that $\left(R^{p}-1\right) / R^{p}>a^{1 / \mu}$ when $\mu>0$ and that $\left(R^{*}-1\right) / R^{*}<a^{1 / \mu}$ when $\mu<0$. Given all other parameter values, these restrictions are satisfied for $a$ sufficiently small.

${ }^{5}$ An additional restriction that solutions to (16) must satisfy in order to be able to be supported as equilibrium real allocation is that $\left(\frac{1-a^{1 /(1-\mu)}}{1-a}\right)^{-1 / \mu} \bar{y}>y_{t}>(1-a)^{1 / \mu} \bar{y}$ when $\mu>0$ and $\left(\frac{1-a^{1 /(1-\mu)}}{1-a}\right)^{-1 / \mu} \bar{y}<$ $y_{t}<(1-a)^{1 / \mu} \bar{y}$ when $\mu<0$. These constraints ensure that $R_{t} \geq 1$ and that $m_{t}$ is a positive real number.
} 
where $\widehat{y}_{t}$ denotes the log-deviation of $y_{t}$ from its steady-state value. The parameter $\epsilon_{R}<0$ denotes the elasticity of the function $R(\cdot)$, defined by equation (15), with respect to $y_{t}$ evaluated at the steady-state value of output. Finally, $\epsilon_{\rho}>0$ denotes the elasticity of the interest-rate feedback rule with respect to inflation at the steady state.

Consider first the passive steady state. As shown above, in this case the feedback-rule is passive, that is, $\epsilon_{\rho}<1$. It follows that the coefficient of the linear difference equation (17) is greater than one. With $y_{t}$ being a non-predetermined variable, this implies that the passive steady state is locally the unique perfect-foresight equilibrium.

Now consider the local equilibrium dynamics around the active steady state. By assumption, at the active steady state $\epsilon_{\rho}$ is greater than 1 . This implies that the coefficient of the difference equation (17) is less than unity. For mildly active policy rules, that is, $\epsilon_{\rho}$ close to one, the coefficient of (17) is less than one in absolute value. Consequently, in this case the rational expectations equilibrium is indeterminate. It follows from our analysis that the parameter value $\epsilon_{\rho}=1$ is a bifurcation point of the dynamical system (17), because at this value the stability properties of the system changes in fundamental ways.

For sufficiently active policy rules, a second bifurcation point might emerge. In particular, if $\epsilon_{R} / \sigma<-2$, then there exists an $\epsilon_{\rho}>1$ at which the coefficient of the linear difference equation (17) equals minus 1. Above this value of $\epsilon_{\rho}$ the coefficient of the difference equation is greater than one in absolute value and the equilibrium is locally unique, as in the neighborhood of the passive steady state.

One might conclude from the above characterization of local equilibria that as long as the policymaker peruses a sufficiently active monetary policy, he can guarantee a unique equilibrium around the inflation target $\pi^{*}$. In this sense active monetary policy might be viewed as stabilizing. However, this view can be misleading. For the global picture can look very different. We turn to this issue in the next subsection.

\subsection{Chaos}

Consider the case of a sufficiently active monetary policy stance that ensures that the inflation target of the central bank, $\pi^{*}$, is locally the unique equilibrium. Formally, assume that at the active steady state $\epsilon_{\rho}>1 /\left(1+2 \sigma / \epsilon_{R}\right) .{ }^{6}$ Such a monetary policy, while stabilizing from a local perspective, may be quite destabilizing from a more global perspective. In particular, there may exist equilibria other than the active steady-state, with the property that the real allocation fluctuates forever in a bounded region around the target allocation. These equilibria include cycles of any periodicity and even chaos (i.e., non-periodic deterministic cycles). To address the possibility of these disturbing equilibrium outcomes, we first establish theoretically the conditions under which periodic and chaotic dynamics exist. We then show that these conditions are satisfied under plausible parameterizations of our simple model economy.

\footnotetext{
${ }^{6}$ We are implicitly assuming that the second bifurcation point exists, that is, that the condition $\epsilon_{R} / \sigma<-2$ is satisfied.
} 


\subsubsection{Existence}

To show the existence of chaotic fluctuations, we apply a theorem due to Yamaguti and Matano (1979) on chaotic dynamics in scalar systems. To this end, we introduce the following change of variable:

$$
q_{t}=\mu \ln \left(\frac{y_{t}}{y^{p}}\right)
$$

Equation (16) can then be written as

$$
q_{t+1}=H\left(q_{t} ; \alpha\right) \equiv q_{t}+\alpha h\left(q_{t}\right),
$$

where the parameter $\alpha$ and the function $h(\cdot)$ are defined as

$$
\alpha=\left(\frac{1}{\sigma}\right)
$$

and

$$
h\left(q_{t}\right)=(-\mu)\left[\ln \left(\rho^{-1}\left(R\left(y^{p} e^{q_{t} / \mu}\right)\right)-\ln \beta-\ln R\left(y^{p} e^{q_{t} / \mu}\right)\right] .\right.
$$

We restrict attention to negative values of $\mu$. As we discuss below, this is the case of greatest empirical interest. The function $h$ is continuous and has two zeros, one at $q=0$ and the other at $q^{*} \equiv \mu \ln \left(y^{*} / y^{p}\right)>0$. Further $h$ is positive for $q_{t} \in\left(0, q^{*}\right)$ and negative for $q_{t} \notin\left[0, q^{*}\right]$. To see this, note that $h(q)$ is simply the natural logarithm of $\left[\beta^{-1} \pi / \rho(\pi)\right]^{(-\mu)}$ and that $\pi$ is a monotonically increasing function of $q$. As can be seen from figure $1, \beta^{-1} \pi$ is equal to $\rho(\pi)$ at the passive and active steady states $\left(\pi^{p}\right.$ and $\left.\pi^{*}\right)$, is greater than $\rho(\pi)$ between the two steady states $\left(\pi \in\left(\pi^{p}, \pi^{*}\right)\right)$, and is smaller than $\rho(\pi)$ outside this range $\left(\pi \notin\left[\pi^{p}, \pi^{*}\right]\right)$. It follows that the differential equation $\dot{x}=h(x)$ has two stationary (steady-state) points, 0 and $q^{*}$. In addition, the stationary point $q^{*}$ is asymptotically stable.

We are now ready to state the Yamaguti and Matano (1979) theorem.

Theorem 1 (Yamaguti and Matano (1979)) Consider the difference equation

$$
q_{t+1}=H\left(q_{t} ; \alpha\right) \equiv q_{t}+\alpha h\left(q_{t}\right)
$$

Suppose that (a) $h(0)=h\left(q^{*}\right)=0$ for some $q^{*}>0$; (b) $h(q)>0$ for $0<q<q^{*}$; and (c) $h(q)<0$ for $q^{*}<q<\kappa$, where the constant $\kappa$ is possibly $+\infty$. Then there exists a positive constant $c_{1}$ such that for any $\alpha>c_{1}$ the difference equation (19) is chaotic in the sense of Li and Yorke (1975).

Suppose in addition that $\kappa=+\infty$. Then there exists another constant $c_{2}, 0<c_{1}<c_{2}$, such that for any $0 \leq \alpha \leq c_{2}$, the map $H$ has an invariant finite interval $[0, \gamma(\alpha)]$ (i.e., $H$ maps $[0, \gamma(\alpha)]$ into itself) with $\gamma(\alpha)>q^{*}$. Moreover, when $c_{1}<\alpha \leq c_{2}$, the above-mentioned chaotic phenomenon occurs in this invariant interval.

The application of this theorem to our model economy is immediate. It follows that there exist parameterization of the model for which the real allocation cycles perpetually in a chaotic fashion, that is, deterministically and aperiodically. According to the theorem, chaotic dynamics are more likely the larger is the intertemporal elasticity of substitution, $1 / \sigma$. We next study the empirical plausibility of the parameterizations consistent with chaos. 


\subsubsection{Empirical plausibility}

To shed light on the empirical plausibility of the existence of chaotic equilibria under active monetary policy, consider the following calibration of the model economy. The time unit is a quarter. Let the intended nominal interest rate be 6 percent per year $\left(R^{*}=1.06^{1 / 4}\right)$, which corresponds to the average yield on 3-month U.S. Treasury bills over the period 1960:Q1 to 1998:Q3. We set the target rate of inflation at 4.2 percent per year $\left(\pi^{*}=1.042^{1 / 4}\right)$. This number matches the average growth rate of the U.S. GDP deflator during the period 1960:Q1-1998:Q3. The assumed values for $R^{*}$ and $\pi^{*}$ imply a subjective discount rate of 1.8 percent per year. Following Taylor (1993), we set the elasticity of the interest-rate feedback rule evaluated at $\pi^{*}$ equal to 1.5 (i.e., $A / R^{*}=1.5$ ).

There is a great deal of uncertainty about the value of the intertemporal elasticity of substitution $1 / \sigma$. In the real-business-cycle literature, authors have used values as low as 1/3 (e.g., Rotemberg and Woodford, 1992) and as high as 1 (e.g., King, Plosser, and Rebelo, 1988). In the baseline calibration, we assign a value of 1.5 to $\sigma$. We will also report the sensitivity of the results to variations in the value assumed for this parameter.

Equations (6) and (14) imply a money demand function of the form

$$
m_{t}=y_{t}\left(\frac{R_{t}-1}{a R_{t}}\right)^{1 /(\mu-1)} .
$$

Using U.S. quarterly data from 1960:Q1 to 1999:Q3, we estimate the following money demand function by OLS: ${ }^{7}$

$$
\begin{gathered}
\ln m_{t}=0.0446+0.0275 \ln y_{t}-0.0127 \ln \left(\frac{R_{t}-1}{R_{t}}\right)+1.5423 \ln m_{t-1}-0.5918 \ln m_{t-2} \\
t \text {-stat }=(1.8,4.5,-4.7,24.9,-10.0) \\
R^{2}=0.998 ; \quad D W=2.18 .
\end{gathered}
$$

We obtain virtually the same results using instrumental variables. ${ }^{8}$ The short-run log-log elasticity of real balances with respect to its opportunity cost $\left(R_{t}-1\right) / R_{t}$ is -0.0127 , while the long-run elasticity is -0.2566 . The large discrepancy between the short- and long-run interest rate elasticities is due to the high persistence of real balances in U.S. data. This discrepancy has been reported in numerous studies on U.S. money demand (see, for example, Goldfeld, 1973; and Duprey, 1980). Our model economy does not distinguish between shortand long-run money demand elasticities. Thus, it does not provide a clear guidance as to which estimated elasticity to use to uncover the parameter $\mu$. Were one to use the short-run elasticity, the implied value of $\mu$ would be -77 . The value of $\mu$ falls to -3 when one uses the long-run money demand elasticity. In the baseline calibration of the model, we will assign a value of -9 , which implies a log-log interest elasticity of money demand of -0.1 . We will also show results for a variety of other values within the estimated range. ${ }^{9}$

\footnotetext{
${ }^{7}$ We measure $m_{t}$ as the ratio of M1 to the implicit GDP deflator. The variable $y_{t}$ is real GDP in chained 1996 dollars. The nominal interest rate $R_{t}$ is taken to be the gross quarterly yield on 3-month Treasury bills.

${ }^{8}$ As instruments we choose the first three lags of $\ln y_{t}$ and $\ln \left(R_{t}-1\right) / R_{t}$, and the third and fourth lags of $\ln m_{t}$.

${ }^{9} \mathrm{An}$ alternative strategy would be to build a model where lagged values of real balances emerge endogenously as arguments of the liquidity preference function. However, such exercise is beyond the scope of this paper.
} 
Table 1: Calibration

\begin{tabular}{|c|c|c|c|c|c|c|c|}
\hline \hline$\beta$ & $\sigma$ & $\mu$ & $a$ & $\bar{y}$ & $\pi^{*}$ & $R^{*}$ & $\mathrm{~A}$ \\
\hline 0.996 & 1.5 & -9 & 0.000352 & 1 & 1.0103 & 1.0147 & 1.522 \\
\hline \hline
\end{tabular}

Note: The time unit is 1 quarter.

Figure 2: Forward-Looking Taylor Rules: Three-Period Cycles
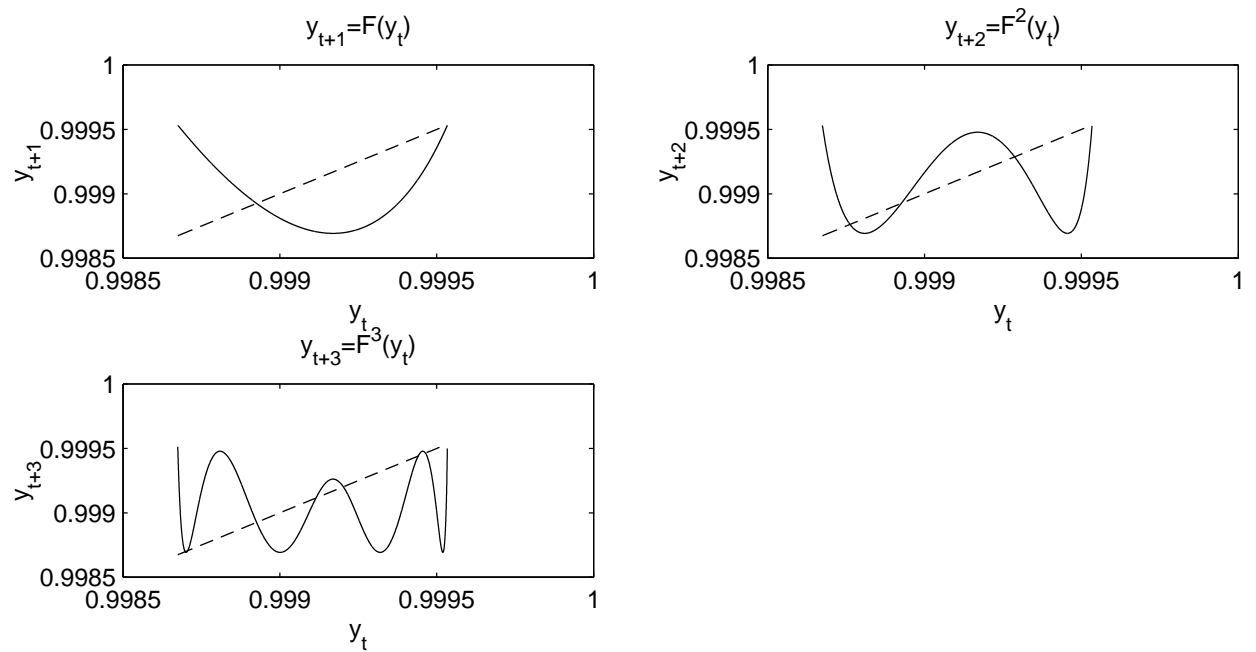

To calibrate the parameter $a$ of the production function, we solve the money demand equation (20) for $a$ and obtain

$$
a=\frac{R_{t}-1}{R_{t}}\left(\frac{m_{t}}{y_{t}}\right)^{1-\mu}
$$

We set $m_{t} / y_{t}=4 / 5.8$ to match the average quarterly U.S. M1 to GDP ratio between 1960:Q1 and 1999:Q3. We also set $\mathrm{R}$ to $1.06^{1 / 4}$ as explained above. Given the baseline value of $\mu$, the implied value of $a$ is $0.000352 .{ }^{10}$ Finally, we set the fixed factor $\bar{y}$ at 1 . Table 1 summarizes the calibration of the model.

Figure 2 shows the first three iterates of the difference equation (16), which describes the equilibrium dynamics of output, for the baseline calibration. In all of the three panels, the straight line is the $45^{\circ}$ degree line and the range of values plotted for output starts at the active steady state, $y^{*}$, and ends at the passive steady state, $y^{p}$. The figure shows that the second- and third iterates of $F$ have fixed points other than the steady-state values $y^{*}$ and $y^{p}$. This means that there exist two- and three-period cycles. The presence of three-period cycles is of particular importance. For, by Sarkovskii's (1964) theorem, the existence of period-three cycles implies that the map $F$ has cycles of any periodicity. Moreover, as a consequence of the result of $\mathrm{Li}$ and Yorke (1975), the existence of period-three cycles implies chaos. That is, for the baseline calibration there exist perfect-foresight equilibria in which the real allocation fluctuates perpetually in an aperiodic fashion.

\footnotetext{
${ }^{10}$ In calibrating $a$, we do not use the estimated constant in our money demand regression. The reason is that the model features a unit income elasticity of money demand whereas the regression equation does not.
} 
Indeed, three-period cycles emerge for any value of $\sigma$ below 1.75. This finding is line with theorem 1, which states that there exists a value for $\sigma$ below which chaotic dynamics necessarily occur. On the other hand, for values of $\sigma$ greater than 1.75, three-period cycles disappear. This does not mean, however, that for such values of $\sigma$ the equilibrium dynamics cannot be quite complex. For example, for $\sigma$ between 1.75 and 1.88, we could detect sixperiod cycles. Sarkovskii's theorem guarantees that if six-period cycles exist, then cycles of periodicities $2^{n} 3$ for all $n \geq 1$ also exist. For $\sigma$ between 1.88 and 2 period-four and period-two cycles exist. ${ }^{11}$

We find that for values of $\mu$ less than -7.5 , the economy has three-period cycles when all other parameters take their baseline values. On the other hand, for values of $\mu$ greater than -7.5 three-period cycles cease to exist. Therefore, the more inelastic is the money demand function, the more likely it is that chaotic dynamics emerge.

\section{Equilibrium dynamics under contemporaneous Tay- lor rules}

Consider the case that the interest-rate feedback rule depends on a contemporaneous measure of inflation, that is, $j=0$ in equation (13). For simplicity, in this section we focus on a special parameterization of the production function given in (14). Specifically, we assume that the elasticity of substitution between real balances and the fixed factor of production is one, $1 /(1-\mu)=1$ and normalize the fixed factor to unity. Then the production function can be written as:

$$
y_{t}=m_{t}^{a}
$$

An equilibrium real allocation is then defined as a set of sequences $\left\{m_{t}, R_{t}, c_{t}, \pi_{t}, y_{t}\right\}_{t=0}^{\infty}$ satisfying $R_{t}>1$, (5), (6), (12), (13) (with $j=0$ ), and (21). Combining these equilibrium conditions yields the following first-order non-linear difference equation describing the equilibrium law of motion of the nominal interest rate:

$$
\frac{R^{*}}{R_{t}}\left[\frac{R_{t}-1}{R_{t}}\right]^{\frac{\sigma a}{1-a}}=\left(\frac{R^{*}-1}{R_{t+1}-1}\right)^{\left(R^{*}-1\right) / A}\left[\frac{R_{t+1}-1}{R_{t+1}}\right]^{\frac{\sigma a}{1-a}} .
$$

\subsection{Local equilibria}

To characterize local equilibrium dynamics, we log-linearize (22) around the steady state $R^{s s}$, where $R^{s s}$ takes the values $R^{*}$ or $R^{p}$. This yields:

$$
\widehat{R}_{t+1}=\theta \widehat{R}_{t}
$$

where

$$
\theta \equiv \frac{\delta\left(R^{s s}\right)-1}{\delta\left(R^{s s}\right)-\frac{R^{*}-1}{R^{s s}-1} \frac{R^{s s}}{A}}
$$

\footnotetext{
${ }^{11}$ For $\sigma>1.71$, the aforementioned cycles occur in a feasible invariant interval. That is, in a feasible interval $A$ such that $F(A) \in A$. The interval $A$ contains both steady states. The upper end of the interval coincides with $y^{p}$ and the lower end is below $y^{*}$. In terms of the notation of the Yamaguti and Matano (1979) theorem, the values of $1 / \sigma$ of $1 / 1.75$ and $1 / 1.71$ correspond to the constants $c_{1}$ and $c_{2}$, respectively.
} 
and

$$
\delta\left(R^{s s}\right) \equiv \frac{\sigma a}{1-a} \frac{1}{R^{s s}-1}>0 .
$$

The variable $\widehat{R}_{t} \equiv \ln \left(R_{t} / R^{s s}\right)$ denotes the log-deviation of $R_{t}$ from its steady-state level. We are interested in parameter specifications for which the intended steady-state $R^{*}$ is locally unique, or $|\theta|>1$. Because of our maintained assumption that $A / R^{*}>1$, the local uniqueness of the active steady-state equilibrium $R^{*}$ requires that $\delta\left(R^{*}\right)<1$. Then, the active steady state is locally unique if: ${ }^{12}$

$$
\delta\left(R^{*}\right)<\frac{1+R^{*} / A}{2} .
$$

This condition implies that the equilibrium is locally unique at the active steady state when $a$ tends to zero, that is, when the interest elasticity of output vanishes. This type of determinacy result is the one emphasize in the recent literature favoring active (or Taylor-type) interest rate rules. On the other hand, when the interest elasticity of output is sufficiently large, equilibrium is locally indeterminate under active interest rate rules. This latter case reflects a more general result stressed in Benhabib, Schmitt-Grohé, and Uribe (2001b). Namely, that whether an active monetary stance will bring about local stability hinges crucially on the precise way in which money is assumed to affect aggregate demand and supply.

Under the baseline calibration presented in the previous section, the active steady state is locally indeterminate. ${ }^{13}$ More generally, given all other parameter values, the active steadystate equilibrium is locally unique for $\sigma<1.21$ and locally indeterminate for $\sigma>1.21$. As under forward-looking rules, under contemporaneous rules values of $\sigma$ for which the target steady state is locally unique need not be associated with global stability. For in this case periodic and even chaotic dynamics easily arise. This issue is the focus of the next section.

\subsection{Periodic and chaotic dynamics}

In this section, we characterize equilibrium fluctuations in which the real allocation remains bounded but does not converge to either steady state. Equation (22) implicitly defines the correspondence $F$ such that

$$
R_{t+1}=F\left(R_{t}\right) .
$$

We construct the graph of this correspondence with the help of figure 3. Consider first the left hand side (LHS) of (22) as a function of $R_{t}$. This relation is shown in the bottom right quadrant of figure 3. The function LHS is nonnegative and continuous in $R_{t}$ for all $R_{t} \geq 1$. It takes the value 0 at $R_{t}=1$ and as $R_{t}$ approaches infinity. Moreover, for $R_{t}>1$, LHS has a single critical point at $R_{t}=R_{L H S}^{c} \equiv 1+\frac{\sigma a}{1-a}>1$, where it reaches a maximum. The top left quadrant of figure 3 shows the right hand side (RHS) of equation (22) as a function of $R_{t+1}$. The function RHS is positive and continuous for all $R_{t+1}>1$. At $R_{t+1}=1$, RHS equals 0 if $\delta\left(R^{*}\right)>1 / A$ or infinity if $\delta\left(R^{*}\right)<1 / A$. Figure 3 is drawn under the assumption that $\delta\left(R^{*}\right)>1 / A$. We will maintain this assumption throughout this section. In this case, RHS

\footnotetext{
${ }^{12}$ Note that at the active steady state $\theta$ is not defined when $\delta\left(R^{*}\right)=R^{*} / A$.

${ }^{13}$ Note that the calibrated value of $a$ depends on the particular value chosen for $\mu$. When $\mu=0$ we have that $a=0.010$.
} 
Figure 3: Contemporaneous Interest-Rate Rules: Graph of Equilibrium Correspondence

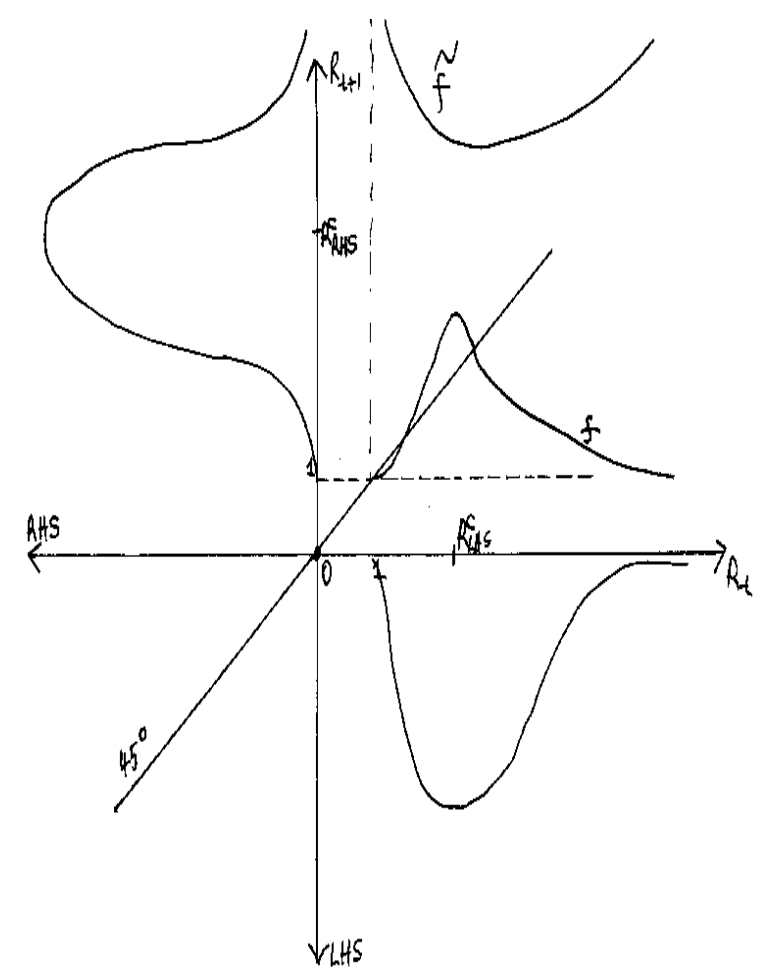


is singled peaked at $R_{t+1}=R_{R H S}^{c} \equiv \delta\left(R^{*}\right) A$. Further, we will assume that the maximum of LHS is less than the maximum of RHS (i.e., $\operatorname{LHS}\left(R_{L H S}^{c}\right)<\operatorname{RHS}\left(R_{R H S}^{c}\right)$ ). Then, for values of $R_{t}>1$ the correspondence $F$ assigns for each value of $R_{t}$ two values of $R_{t+1}$, which define the pair of continuously differentiable functions $f$ and $\tilde{f}$ depicted in the top right quadrant of figure $3 .^{14}$ Clearly, a sufficient condition for the steady state values $R^{p}$ and $R^{*}$ to lie on $f$ (rather than on $\tilde{f}$ ) is that $R^{*}<R_{R H S}^{c}$. We will assume that this sufficient condition is satisfied. Summarizing, to ensure that the correspondence $F$ has the form shown in figure 3, we assume that:

$$
\delta\left(R^{*}\right) A>R^{*}
$$

and

$$
\operatorname{RHS}\left(R_{\mathrm{RHS}}^{c}\right)>\operatorname{LHS}\left(R_{\mathrm{LHS}}^{c}\right)
$$

Figure 3 shows that in the model under study, contemporaneous interest-rate rules may give rise to instantaneous indeterminacy, or non-uniqueness of the temporary equilibrium, in the sense that for a given value of $R_{t}$ there might exist two distinct values of $R_{t+1}$ consistent with an equilibrium real allocation. This is a type of instability that is absent under forward-looking rules. We will limit our analysis to pointing the possibility of instantaneous multiplicity without characterizing it in further detail. ${ }^{15}$

In what follows, we focus on equilibrium real allocations generated by iterates of the map $f$. That is, we will characterize the dynamics of $R_{t}$ generated by the difference equation

$$
R_{t+1}=f\left(R_{t}\right) ; \quad R_{0}>1 .
$$

Under the maintained assumptions (26) and (27), the map $f$ is continuously differentiable, bounded below by unity, unimodal, and satisfies $\lim _{R \rightarrow 1} f(R)=1, f\left(R^{p}\right)=R^{p}, f\left(R^{*}\right)=R^{*}$, and $\lim _{R \rightarrow \infty} f(R)=1 .{ }^{16}$ As mentioned earlier, we wish to restrict attention to situations in which the intended steady state $R^{*}$ is locally unique. Thus, we assume that condition (24) holds. This condition in combination with (26) implies that $f^{\prime}\left(R^{*}\right)<-1$. Because $f$ is continuous, it is clear that at the passive steady state $R^{p}$ it must be the case that $f^{\prime}\left(R^{p}\right) \geq 1$. We will assume that $f^{\prime}\left(R^{p}\right)$ is strictly greater than one. Indeed, one can show that if $(24)$ and (26) are satisfied and $R^{*} \in(1,2)$, then $f^{\prime}\left(R^{p}\right)=1$ can be ruled out, for in this case $\lim _{R \rightarrow 1} f^{\prime}(R)=0$.

It follows that $f$ has a cycle of period 2. To see this, let $f^{2}=f \circ f$ be the second iterate of $f$. Then $f^{2}\left(R^{p}\right)=R^{p}$ and $f^{2}\left(R^{*}\right)=R^{*}$. Moreover, $f^{2^{\prime}}\left(R^{p}\right)=\left[f^{\prime}\left(R^{p}\right)\right]^{2}>1$ and $f^{2^{\prime}}\left(R^{*}\right)=\left[f^{\prime}\left(R^{*}\right)\right]^{2}>1$. Thus, by continuity we have that there must exist an interest rate $R \in\left(R^{p}, R^{*}\right)$ for which $f^{2}(R)=R$. That is, $f^{2}$ has a fixed point different from $R^{*}$ or $R^{p}$. We summarize this result in the following proposition:

\footnotetext{
${ }^{14}$ If RHS is monotonically decreasing, which is the case when $\delta\left(R^{*}\right)<1 / A$, then the correspondence $F$ is singled valued, continuous, converges to infinity as $R_{t}$ approaches either 1 or infinity, and has a unique critical point that is a global minimum at $R_{L H S}^{c}$.

${ }^{15}$ We also conjecture that equilibria in which the nominal interest rate visits both branches of the correspondence $F$ may feature interest rate trajectories with a lim inf equal to one. Moreover, even if the nominal interest rate remains forever on the lower branch $f$, the nominal interest rate may converge to one. That is, equilibria in which the nominal interest rate is asymptotically equal to zero (liquidity traps) may be possible.

${ }^{16}$ Recall, however, that $R=1$ cannot be supported as an equilibrium real allocation.
} 
Figure 4: Contemporaneous Taylor rules: Three-Period Cycles
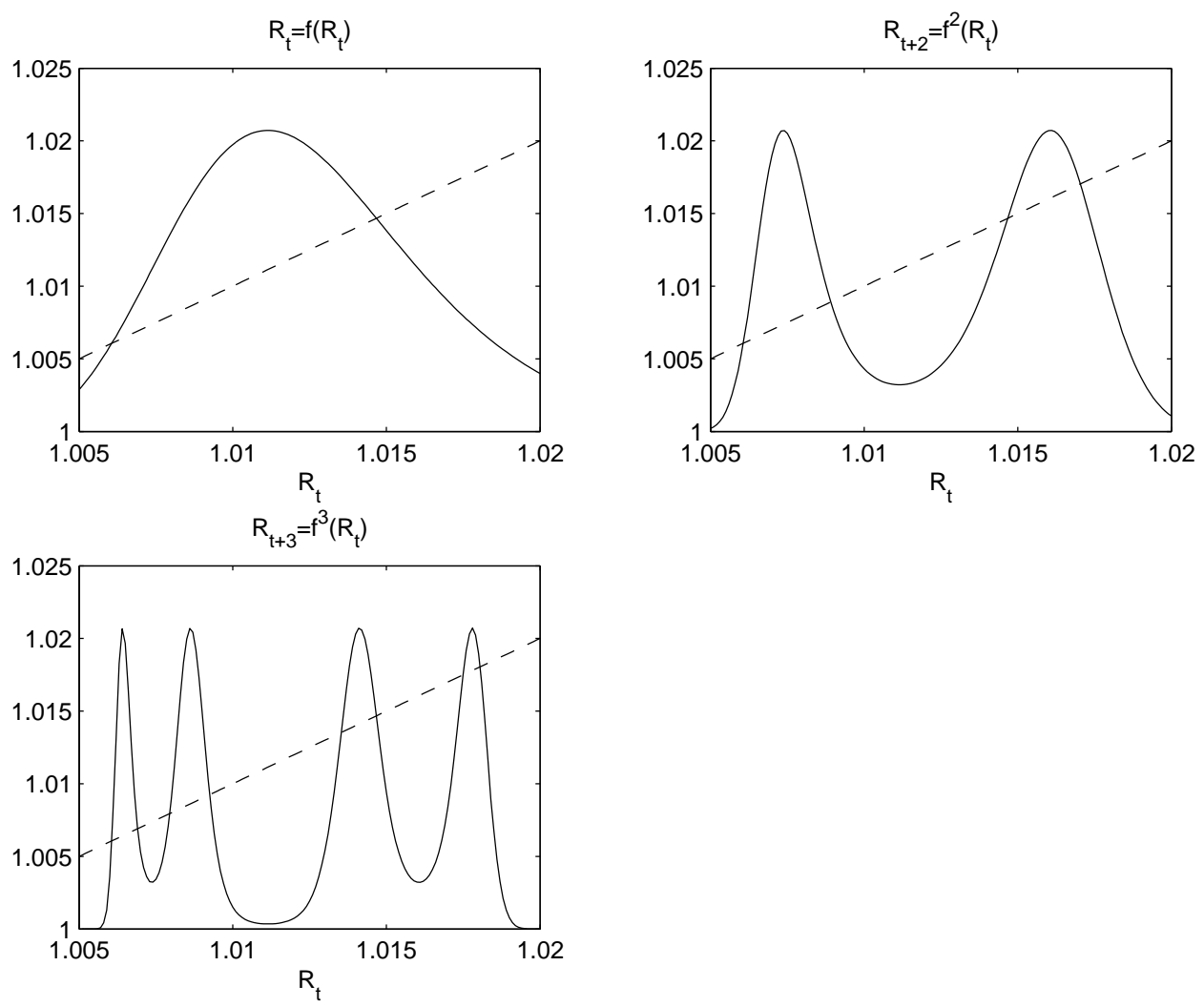

Proposition 1 (Period 2 cycles) If conditions (24), (26), and (27) are satisfied and $R^{*} \in$ $(1,2)$, then the map $f$ defined in (28) has a cycle of period 2.

In the calibration presented in the previous subsection, we established that, given all other parameter values, the intended equilibrium $R^{*}$ is locally unique for values of $\sigma<1.21$. The conditions of proposition 1 are satisfied for all values of $\sigma$ such that $\theta<-1$ (or, equivalently, $\left.f^{\prime}\left(R^{*}\right)<-1\right)$. This is the case if $\sigma \in(0.97,1.21)$.

But 2-period cycles are not the only type of periodic equilibria that may arise in this economy. Indeed, for some ranges of $\sigma$ in the interval $(0.97,1.21)$ there exist cycles of any periodicity. Figure 4 shows the first, second, and third iterates of $f$ for $\sigma$ is equal to 1.1. All other parameters take the values given in the previous subsection. The bottom left panel of the figure shows that the map $f^{3}: R_{t+3}=f^{3}\left(R_{t}\right)$ has four fixed points in the open interval $\left(R^{p}, R^{*}\right)$. Thus, the map $f$ has cycles of period 3. It then follows from Sarkovskii (1964) that $f$ has cycles of any periodicity and from Li and Yorke (1975) that $f$ is chaotic. We have been able to check numerically that period-3 cycles appear for values of $\sigma$ between 1.02 and $1.13 .{ }^{17}$

We conclude that for the case of greatest empirical interest, that is, an intertemporal elasticity of substitution less than one (or $\sigma>1$ ), the real allocation is always indeterminate; either it is locally indeterminate $(\sigma>1.21)$ or it is locally determinate but cycles of various

\footnotetext{
${ }^{17}$ It is difficult to numerically compute the third iterate of $f$ for values of $\sigma$ below 1.02. However, we suspect that $f$ displays period-3 cycles for values of $\sigma$ as low as unity.
} 
periods and even chaos exist.

\section{Discussion and Conclusion}

In this paper we illustrate by means of specific economic environments the point that even if an active interest-rate feedback rule can ensure that the target rate of inflation is locally the unique equilibrium, it may still allow for complex equilibrium dynamics. Specifically, we study a number model economies in which active interest-rate feedback rules give rise to equilibrium cycles of any periodicity and even chaos.

It is important to note that the complex dynamics we identify in this paper cannot be ruled out by "non-Ricardian" fiscal and monetary policies, like a commitment to a strong fiscal stimulus or a switch to a high money growth rate that is automatically activated when inflation begins to decelerate, that have been suggested as being effective in eliminating liquidity traps in the recent literature (see, for example, Woodford, 1999; and Benhabib, Schmitt-Grohé, and Uribe, 2001c). The reason is that the effectiveness of the suggested policies relies on the fact that the interest rate moves permanently below its intended level. By contrast, the equilibria identified in this paper feature trajectories in which the nominal interest rate is bounded away from zero and infinity and cycles above and below the target. It follows that the design of policies capable of eliminating chaotic dynamics remains a subject for future research. ${ }^{18}$

We conclude by pointing out that the main result of this paper is robust to a number of modifications in the underlying theoretical framework. For example, it is noteworthy that the local properties of the "active" steady state do not depend on the assumption that the interest-rate feedback rule is non-linear and respects the zero lower bound on interest rates. Specifically, local indeterminacy with convergence either to an active steady state or to a cycle surrounding it may arise even when the interest-rate rule is linear. To see this, consider the interest-rate rule:

$$
R_{t}=R^{*}+A\left(\frac{\pi_{t+1}-\pi^{*}}{\pi^{*}}\right) .
$$

At the intended inflation rate $\pi^{*}$, this interest-rate feedback rule has the same inflation elasticity, $A / R^{*}$, as the non-linear Taylor rule given by (13), which respects the zero lower bound on the nominal rate. All other elements of the model are as in section 3 . The economy now features a single steady state $y^{*}$. The linearized version of the equilibrium law of motion of output around $y^{*}$ is given by equation (17). Let the feedback rule be active around the steady state, $\epsilon_{\rho}>1$, and consider the local stability properties of the system as one varies the intertemporal elasticity of substitution $1 / \sigma$. Clearly, there is a critical value of $\sigma, \sigma^{c}$, at which the coefficient of the linear system equals -1 . For values of $\sigma$ below $\sigma^{c}$, the slope of the difference equation (17) is greater than one in absolute value and the equilibrium is locally unique. For value of $\sigma$ greater than $\sigma^{c}$, the coefficient has modulus less than one and hence the equilibrium is locally indeterminate. Thus, at $\sigma=\sigma^{c}$ the equilibrium has a flip bifurcation, implying the existence of period-two cycles. Interestingly, it can be shown that

\footnotetext{
${ }^{18}$ Note however the suggestion by Christiano and Rostagno (2001) for implementing a Taylor rule only in a small neighborhood of the target inflation rate with a commitment to switch to a money growth rule outside that neighborhood in order narrow down the range of possible indeterminacy.
} 
when all parameters other than $\sigma$ take their baseline values given in table 1 , asymptotically stable periodic equilibria emerge when the steady state is unique, that is, when $\sigma<\sigma^{c}$. For this calibration, $\sigma^{c}$ is 2.42 and we were able to detect stable cycles of period two for values of $\sigma$ between this critical value and 2.35.

Complex equilibrium dynamics may also emerge under alternative timing conventions regarding the specification of the production technology. ${ }^{19}$ Thus far, we have assumed that money balances chosen in period $t$ affect output in that same period. Alternatively, one could assume that the production function in period $t$ depends on money balances carried over from the previous period. Formally:

$$
y_{t}=f\left(\frac{M_{t-1}}{P_{t}}\right)
$$

Under a forward-looking interest-rate feedback rule, like the one given in equation (13) with $j=1$, the equilibrium law of motion of output may display non-uniqueness of the temporal equilibrium. At the same time, if the interest-rate rule depends on a contemporaneous measure of inflation, as in equation (13) with $j=0$, the equilibrium dynamics take the form of a difference equation of second order and the solution can be complicated.

Recently, the issue of the learnability of rational expectations equilibria has acquired renewed vigor, particularly in monetary economics. The argument of learnability has been used to question the relevance of unintended equilibria that may arise when the central bank follows a Taylor-type interest-rate rule. For example, Bullard and Mitra (2001) find in the context of a sticky-price model à la Woodford (1996) that under an active interest-rate feedback rule the intended equilibrium is learnable if it is determinate under rational expectations. Honkapohja and Mitra (2001) show that the sunspot equilibria that emerge in this class of models when the rational expectations equilibrium is indeterminate are not learnable. However, Carlstrom and Fuerst (2001b) have shown that the Honkapohja and Mitra result is fragile to changes in the way money demand is motivated and in the assumed degree of informational asymmetry between the central bank and the private sector. Specifically, Carlstrom and Fuerst show that under a cash-in-advance transactions technology or when only the central bank but not the private sector is subject to learning, then sunspot equilibria become learnable. These sunspot equilibria emerge when the perfect foresight equilibrium is indeterminate, which in the Woodford sticky-price model that they analyze is the case either when the interest-rate rule is passive or when it is highly active. Recent theoretical work by Evans and Honkapohja (2001) derives conditions under which near an indeterminate steady state $k$-state Markov sunspot equilibria exist that are learnable. Applying their result to our money-in-the-production economy in the case that an active monetary policy renders the equilibrium locally indeterminate, we can establish the existence of learnable sunspot equilibria. An interesting question for future research is to characterize the learnability of the periodic equilibria unearthed in the present study.

\footnotetext{
${ }^{19}$ For a general discussion of various timing assumptions regarding the transaction technology and their impact on local determinacy properties, see Carlstrom and Fuerst (2001a).
} 


\section{References}

Benhabib, Jess, Stephanie Schmitt-Grohé, and Martín Uribe, "The Perils of Taylor Rules," Journal of Economic Theory, 96 (1), January-February 2001(a), 40-69.

Benhabib, Jess; Schmitt-Grohé, Stephanie; and Uribe Martín, "Monetary Policy and Multiple Equilibria," American Economic Review 91, March 2001(b), 167-185.

Benhabib, Jess; Schmitt-Grohé, Stephanie; and Uribe Martín, "Avoiding Liquidity Traps," Journal of Political Economy, 2001c, forthcoming. [available at http://www.econ.upenn.edu/ uribe.]

Bullard, Jim and Kaushik Mitra, "Learning About Monetary Policy Rules," Federal Reserve Bank of St. Louis working paper series No. 2000-001c, February 2001.

Carlstrom, C; and Fuerst, T., "Forward vs. Backward-Looking Taylor Rules," Working paper, Federal Reserve Bank of Cleveland, 2000.

Carlstrom, C; and Fuerst, T., "Timing and Real Indeterminacy in Monetary Models," Journal of Monetary Economics 47, April 2001a , 285-298.

Carlstrom, C; and Fuerst, T., "Learning and the Central Bank," manuscript. Bowling Green: Bowling Green State University, June 26, $2001 \mathrm{~b}$.

Calvo, Guillermo A., "On Models of Money and Perfect Foresight," International Economic Review, 29, February 1979, 83-103.

Christiano, Lawrence J. and Rostagno, Massimo, "Money Growth Monitoring and the Taylor Rule," Manuscript. Evanston: Northwestern University, June 23, 2001.

Clarida, Richard, and Mark Gertler "How the Bundesbank conducts Monetary Policy" In Reducing Inflation: Motivation and Strategies, edited by Christina and David Romer, Chicago: University of Chicago Press, 1997.

Clarida, Richard, Jordi Galí, and Mark Gertler, "Monetary policy rules in practice: some international evidence," European Economic Review 42, 1998, 1033-1067.

Clarida, Richard, Jordi Galí, and Mark Gertler, "Monetary Policy Rules and Macroeconomic Stability: Evidence and Some Theory," The Quarterly Journal of Economics 115, February 2000, 147-80.

Dupor, Bill, "Investment and Interest Rate Policy," Manuscript. Philadelphia: University of Pennsylvania, October 1999.

Duprey, James N, "The Search for a Stable Money Demand Equation," Federal Reserve Bank of Minneapolis Quarterly Review 4, Summer 1980.

Evans, George and Seppo Honkapohja, "Existence of Adaptively Stable Sunspot Equilibria Near An Indeterminate Steady State," manuscript. Helsinki: The University of Helsinki, April 9, 2001.

Fischer, Stanley, "Money and the Production Function," Economic Inquiry, 12, December 1974, 517-33.

Goldfeld, Stephen, "The Demand for Money Revisited," Brookings Papers on Economic Activity, No. 3, 1973.

Honkapohja, Seppo and Kaushik Mitra, "Are Non-Fundamental Equilibria Learnable in Models of Monetary Policy?," manuscript. Helsinki: The University of Helsinki, January 29, 2001.

King, Robert G.; Plosser, Charles I.; and Rebelo, Sergio T., "Production, Growth, and Business Cycles I. The Basic Neoclassical Model," Journal of Monetary Economics, 21, 
March-May 1988, 195-232.

Leeper, Eric, "Equilibria under 'Active' and 'Passive' Monetary and Fiscal Policies," Journal of Monetary Economics 27, 1991, 129-147.

Li, T. and Yorke, J. A., "Period Three Implies Chaos," American Mathematical Monthly, 82, 1975, 985-992.

Orphanides, Athanasios, "Monetary Policy Rules Based On Real Time Data," Finance and Economic Discussion Series No. 1998-03, Federal Reserve Board, 1997.

Rotemberg, Julio J. and Woodford, Michael D., "Oligopolistic Pricing and the Effects of Aggregate Demand on Economic Activity," Journal of Political Economy, 100, December 1992, 1153-1207.

Rotemberg, Julio and Woodford, Michael "Interest-Rate Rules in an Estimated Sticky-Price Model" In Monetary Policy Rules, edited by John B. Taylor, Chicago: University of Chicago Press, 1999.

Sarkovskii, A. N., "Coexistence of Cycles of a Continuous Map of the Line Into Itself," Ukrain. Matem. Zhur., 16, 1964, 61-71.

Schmitt-Grohé, Stephanie and Martín Uribe, "Price Level Determinacy and Monetary Policy Under a Balanced-Budget Requirement," Journal of Monetary Economics 45, February 2000a, 211-246.

Schmitt-Grohé, Stephanie and Martín Uribe, "Liquidity Traps with Global Taylor Rules," manuscript. Philadelphia: University of Pennsylvania, July 2000b. [available at http://www.econ.upenn.edu/ uribe.]

Taylor, John B., "Conditions for Unique Solutions in Stochastic Macroeconomic Models with Rational Expectations," Econometrica 45, September 1977, 1377-1385.

Taylor, John B., "Discretion Versus Policy Rules in Practice," Carnegie-Rochester Conference Series on Public Policy 39, December 1993, 195-214.

Taylor, John B. "A Historical Analysis of Monetary Policy Rules" In Monetary Policy Rules, edited by John B. Taylor, University of Chicago Press, 1999: 319-341.

Yamaguti, M. and Matano, H., "Euler's Finite Difference Scheme and Chaos," Proceedings of the Japanese Academy of Sciences (Ser. A), 55, 1979, 78-80.

Woodford, Michael, "Control of Public Debt: A Requirement for Price Stability," NBER working paper No. 5684, July 1996.

Woodford, Michael, "Self-fulfilling Inflations and Deflations," in Interest and Prices, Chapter 1.4, Princeton University, April 22, 1999. 